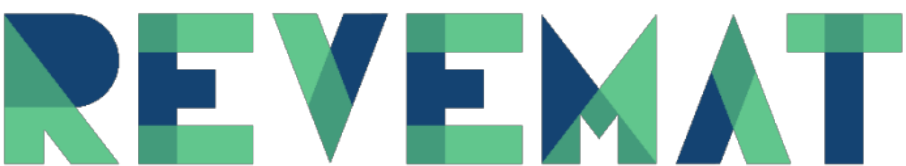

REVISTA ELETRÔNICA DE EDUCAÇÃO MATEMÁTICA

\title{
INVESTIGAÇÃO-HISTÓRICA-COM-TECNOLOGIA PARA A UNIDADE DE ÁLGEBRA E GEOMETRIA NO $8^{\circ}$ ANO Investigation-History-With-Technology for the Algebra and Geometry Unit in the 8th Year
}

\author{
Giselle Costa de SOUSA \\ Universidade Federal do Rio Grande do Norte, Natal, Brasil \\ gisellecsousa@hotmail.com \\ https://orcid.org/0000-0003-0213-4179 \\ Alison Luan Ferreira da SILVA \\ Secretaria Estadual de Educação e Cultura do Rio Grande do Norte, Natal, Brasil \\ alisonfera2007@gmail.com \\ https://orcid.org/0000-0003-4763-8629
}

A lista completa com informações dos autores está no final do artigo

\begin{abstract}
RESUMO
A História da Matemática (HM), as Tecnologias Digitais da Informação e Comunicação (TDIC) e Investigação Matemática (IM), dentre outras, são tendências em educação matemática cujas pesquisas tem apontado para argumentos favoráveis de uso no ensino-aprendizagem de matemática. Há ainda a possibilidade de uni-las em prol do ensino e aprendizagem. Em se tratando do ensino básico, recomenda-se que as propostas sejam apoiadas nos documentos oficiais, dentre eles a Base Nacional Comum Curricular (BNCC) que igualmente recomenda essas tendências e ainda sua conexão. Deste modo, nesse artigo, propomos a aliança entre HM, TDIC via IM mediante a apreciação de parte de um produto educacional, para abordagem das unidades temáticas de Álgebra e Geometria mediante os objetos de conhecimentos de plano cartesiano e transformações geométricas como simetria, tratados com abordagem histórica de personagens, obras e documentos como Nicole Oresme, La Géométrie de Descartes, o Problema de Pappus, a pintura rupestre do Abrigo de Rock El Buey, observação das esfinges esmaltadas do palácio de Dario em Susa, entre outros. Para isso, nossa pesquisa adota abordagem qualitativa com objetivo exploratório de modo a introduzir constructos que fundamentam a proposta e apresentar exemplo específico que caracteriza a aliança supracitada. Como resultado encontramos objetos de conhecimentos comuns as unidades temáticas supracitadas podendo ser abordados numa investigação-histórica-comtecnologia mediante produto educacional, concluindo que esta proposta consiste numa alternativa para abordagem matemática na educação básica na direção da conjunção entre HM, TDIC e IM.
\end{abstract}

Palavras-chave: Investigação-histórica-com-tecnologia, Unidades de Álgebras e Geometria, Plano cartesiano, Simetria

\section{ABSTRACT}

The History of Mathematics (HM), Digital Technologies of Information and Communication (TDIC) and Mathematical Investigation (IM), among others, are trends in mathematical education whose research has pointed to favorable arguments for use in the teaching-learning of mathematics. There i salso the possibility of uniting them for the sake of teaching and learning. In the case of basic education, it is recommended that the proposals be supported by oficial documents, among them the National Common Curricular Base (BNCC) which also recommends these trends and also their connection. Thus, in this article, we propose the aliance between HM, TDIC through IM through the appreciation of parto of an education product, to approach the thematic units of Numbers and Probability and Statistics by means of the knowledge object cartesian knowledge objects and geometric transformations such as symmetry, treated with a historical approach to 
characters, works and documents such as Nicole Oresme, Descartes'La Géométrie, the Pappus Problem, the rock painting of the Shelter of Rock El Buey, observation of enameded sphinxes of the palace of Darius in Susa, among others. For this, our research adopts a qualitative approach with an exploratory objective in order to introduce constructs that support the proposal and presente a specific example that caracterizes the aforomentioned aliance. As a result, we find the objects of common knowledge, the thematic units mentioned above can be approached in a historical-with-tecnology investigation through an education product, concluding that this proposal is an alternative approach mathematics in basic education towards the conjunction between HM, TDIC and IM.

Keywords/Palabras clave: Historical-research-with-technology, Units of Algebras and Geometry, Cartesian Plane, Symmetry

\section{INTRODUÇÃO}

Com aporte na relevância em três das tendências da educação matemática, a saber: o uso da História da Matemática (HM), das Tecnologias Digitais da Informação e Comunicação (TDIC) e da Investigação Matemática (IM) e atestado na literatura de referência da área, ou seja, à luz do processo de investigação matemática de Ponte, Brocardo e Oliveira (2005), dos argumentos favoráveis ao uso de história na educação matemática de Miguel e Miorim (2004), bem como, das considerações de Borba e Penteado (2007) acerca da informática e educação matemática, consideramos importante o potencial de cada uma delas de modo independente. Contudo, creditamos que sua conexão pode também ser uma proposta didática para abordagem matemática a partir do que nomeamos como investigação-histórica-com-tecnologia1.

Considerando esses aspectos, a pesquisa aqui exibida tem por objetivo apresentar e descrever uma investigação-histórica-com-tecnologia para unidade de Álgebra e de Geometria da BNCC para o $8^{\circ}$ ano do ensino fundamental por meio da conexão entre três tendências em educação matemática a partir dos objetos de conhecimento plano cartesiano e transformações geométricas tratado por abordagem histórica de personagens, obras, problemas e documentos. Para tanto, adota abordagem metodológica qualitativa com objetivo exploratório, considerando que, segundo Pereira et al. (2018, p. 67) "os métodos qualitativos são aqueles nos quais é importante a interpretação por parte do pesquisador com suas opiniões sobre o fenômeno em estudo" tendo, como coloca Ludcke e Andre (2013), meta exploratória a medida que os dados obtidos são preferencialmente descritivos, o que de fato nos propomos a fazer ao longo deste texto quando almejamos uma maior familiaridade com o problema da apresentação de proposta da aliança entre HM e TDIC via

\footnotetext{
${ }^{1}$ É a união da Investigação Matemática com a História da Matemática e as Tecnologias Digitais da Informação e Comunicação em prol do ensino e aprendizagem de matemática. Essa união acontece a partir da abordagem de problemas históricos que podem ser investigados com o apoio de recursos tecnológicos.
} 
IM de modo que busca compreender de uma forma mais ampla e subjetiva o que está sendo pesquisado (Gil, 2007). Assim, introduz constructos que fundamentam a proposta e exibe exemplo que assinala a aliança mencionada.

\section{APRESENTAÇÃO/DESCRIÇÃO DA PROPOSTA}

Ao propor uma sugestão no âmbito da educação básica nos respaldamos nas recomendações da BNCC (Brasil, 2017) sobre a HM, TDIC e IM e adotamos um estudo de suas unidades temáticas do ensino fundamental anos finais, de tais, escolhemos $\circ 8^{\circ}$ ano em razão de um dos pesquisadores lecionar neste nível de ensino. Portanto, produzimos uma dissertação de mestrado intitulada História da Matemática, Tecnologias Digitais e Investigação Matemática no ensino de unidades temáticas de matemática da BNCC para o $8^{\circ}$ ano e esta, por sua vez, elaborou um produto educacional nomeado por História, Tecnologias e Matemática: uma aliança potencial para conteúdos do $8^{\circ}$ ano. Tal material consiste num caderno de tarefas organizadas em 3 blocos os quais abordam problemas de HM associados às TDIC em articulação com a IM de acordo com as unidades temáticas da BNCC para as turmas do $8^{\circ}$ ano do ensino fundamental anos finais.

Esclarecendo, o primeiro deles articula a unidade de Números (unidade 1) e a unidade de Probabilidade e Estatística (unidade 5). A referida seleção se deu pela constatação de um objeto de conhecimento comum a essas unidades que consiste no Princípio multiplicativo da contagem. Para abordarmos esse objeto, realizamos um estudo histórico bibliográfico chegando ao Problema das Gavetas de Dirichlet, que, deste modo, foi gerador de nossa investigação-histórica-com-tecnologia para o tratamento das unidades temáticas 1 e 5 da BNCC para o $8^{\circ}$ ano do ensino fundamental anos finais.

O segundo bloco é composto pela união da unidade de Álgebra (unidade 2) e a unidade de Geometria (unidade 3) a partir do tema de transformações geométricas no plano cartesiano, que foi encontrado por um histórico bibliográfico. Assim, tal tema foi gerador de nossa investigação-histórica-com-tecnologia para o tratamento das unidades temáticas 2 e 3 da BNCC para o $8^{\circ}$ ano do ensino fundamental anos finais

O terceiro bloco deste caderno de tarefas decorre da unidade de Grandezas e Medidas (unidade 4) que impulsionou um estudo histórico bibliográfico e nos levou a uma abordagem histórica de um dos três problemas clássicos da Geometria Euclidiana, a quadratura do círculo, também citada pela BNCC (Brasil, 2017, p. 268) ao afirmar que "a 
equivalência de áreas, por exemplo, já praticada há milhares de anos pelos mesopotâmios e gregos antigos sem utilizar fórmulas, permite transformar qualquer região poligonal plana em um quadrado com mesma área" (é o que os gregos chamavam fazer a quadratura de uma figura). Portanto, decidimos abordar a área de figuras planas por meio da quadratura do círculo como tema histórico, tratado com o apoio das TDIC via IM.

No presente artigo nos restringimos a tratar do segundo bloco, conforme detalharemos adiante. Desse modo, o presente trabalho é composto por três partes. A primeira, consiste dessa seção introdutória de apresentação geral do trabalho. A segunda trata do desenvolvimento da pesquisa em que existem os constructos que fundamentam o trabalho e a apresentação da nossa proposta pedagógica de uso da investigação-históricacom-tecnologia para o $8^{\circ}$ ano tendo como eixo central o estudo de plano cartesiano e transformações geométricas juntamente com orientações de uso. Por último, a terceira parte versa das conclusões pensadas a partir da proposta exibida.

\section{FUNDAMENTOS E EXIBIÇÃO DA PROPOSTA}

Desenvolvemos esse artigo adotando uma abordagem de pesquisa qualitativa com objetivo exploratório que, dentre outros aspectos, inclui procedimentos de busca e seleção de trabalhos usados na revisão juntamente com a apreciação de exemplo de proposta pedagógica à luz dos fundamentos postos. De fato, em um artigo científico, de acordo com Pereira et al. (2018, p. 94-95), "está se relatando resultados de alguma descoberta, experiência realizada, descrevendo algum caso, relatando alguma experiência vivida, descrevendo algum fenômeno ocorrido ou ainda fazendo uma revisão bibliográfica em relação a algum tema". Os procedimentos de busca para a fundamentação apresentada consistiram em estudo análitco de trabalhos (livros e artigos) que envolvem HM, TDIC e IM de modo a identificar aspectos comuns a essas tendências em educação matemática os quais, após produção de fichamentos e extração e trechos transcritos, foram separados em categorias, a saber: aspectos, argumentos, autores e relação com produto educacional. Estas, por sua vez, delineiam a aliança aqui proposta entre tais tendências e se ligam às recomendações da BNCC a fim de direcionar a proposta pedagógica apresentada adiante.

Desse modo, o corpo de desenvolvimento exposto nesse momento se constitui das reflexões sobre fundamentos da proposta que discutem os constructos de alicerce, bem como, da articulação da proposta com a BNCC para, em seguida, tratar da apresentação 
da proposta de investigação-histórica-com-tecnologia para as unidades temáticas de Álgebra e Geometria do $8^{\circ}$ ano do ensino fundamental.

\subsection{Fundamentos da proposta}

\subsubsection{Uso da HM articulada por TDIC e IM no ensino de matemática}

Nesse momento expomos a fundamentação que permitiu o entrelaçamento da HM, das TDIC e da IM de tal modo que se tornassem tendências potenciais, comandadas pela História da Matemática num processo uno de aliança, com TDIC e IM que chamamos de investigação-histórica-com-tecnologia.

Para atingir nosso objetivo, selecionamos todos os pontos essenciais em comum dessas três tendências pedagógicas de educação matemática que resultou no quadro 1 que mostra como essas elas convergem e podem ser trabalhadas em conjunto no ensino e aprendizagem da matemática, já que separadamente elas já cumprem esse papel. Desse modo, a ideia é que esses fundamentos norteiem produções na direção de aliança entre HM, TDIC e IM, assim como orientaram a referida proposta. Analisando as bases dessas tendências chegamos a 5 aspectos comuns, a saber: criação humana; fonte de geração do conhecimento investigativo; fonte de resolução de problemas; produção da matemática genuína; e, por fim, que tanto a HM, quanto as TDIC e a IM interferem na relação ensino e aprendizagem da matemática na sala de aula. Tais aspectos serão detalhados e apresentados adiante levando em consideração o que há em comum entre eles, desde os argumentos, passando pelos autores envolvidos, cada um no seu ramo de pesquisa (HM, TDIC e IM) e finalmente a relação com o caderno de tarefas elaborado (aqui representado pelo bloco II).

Quadro 1: investigação-histórica-com-tecnologia

\begin{tabular}{|l|l|l|l|}
\hline \multicolumn{1}{|c|}{ ASPECTOS } & \multicolumn{1}{|c|}{ ARGUMENTOS } & \multicolumn{1}{|c|}{ AUTORES } & \multicolumn{1}{|c|}{$\begin{array}{l}\text { RELAÇÃO COM O } \\
\text { PRODUTO } \\
\text { EDUCACIONAL }\end{array}$} \\
\hline $\begin{array}{l}\text { Apresenta a } \\
\text { matemática } \\
\text { como uma } \\
\text { criação humana }\end{array}$ & $\begin{array}{l}\text { A matemática foi } \\
\text { criada a partir da } \\
\text { necessidade do } \\
\text { homem. Demonstram } \\
\text { que a matemática é } \\
\text { uma ciência em } \\
\text { constante construção } \\
\text { e que sofre alterações } \\
\text { de acordo com a } \\
\text { sociedade na qual } \\
\text { está inserida. }\end{array}$ & $\begin{array}{l}\text { Miguel e Miorim } \\
\text { (2017); Fossa (2008); } \\
\text { D'Ambrósio (1999); }\end{array}$ & $\begin{array}{l}\text { Mendes (2009); } \\
\text { Roque (2012); Lévy } \\
\text { (1999); Ponte, } \\
\text { Brocado e Oliveira } \\
\text { atividades/problemas que } \\
\text { exaltem a atividade } \\
\text { matemática como um } \\
\text { produto da atividade/cultura } \\
\text { humana. Propomos } \\
\text { atividades/problemas para } \\
\text { que o aluno tenha a noção } \\
\text { dessa ciência, como uma } \\
\text { ciência em construção, com }\end{array}$ \\
\hline
\end{tabular}




\begin{tabular}{|c|c|c|c|}
\hline & & & $\begin{array}{l}\text { erros e acertos e sem } \\
\text { verdades universais. }\end{array}$ \\
\hline $\begin{array}{l}\text { Promove a } \\
\text { geração do } \\
\text { conhecimento } \\
\text { investigativo }\end{array}$ & $\begin{array}{l}\text { Construção r do } \\
\text { conhecimento por } \\
\text { meio da investigação } \\
\text { para que o aluno possa } \\
\text { edificar } \\
\text { conhecimento } \\
\text { matemático na forma } \\
\text { de um coletivo formado } \\
\text { por seres-humanos- } \\
\text { com-mídias }\end{array}$ & $\begin{array}{l}\text { Fossa (2008); Ponte, } \\
\text { Brocado e Oliveira } \\
\text { (2016); Borba (2012); } \\
\text { Borba e Penteado } \\
\text { (2012). }\end{array}$ & $\begin{array}{l}\text { Propomos } \\
\text { atividades/problemas com } \\
\text { itens, que contemplem } \\
\text { problemas investigativos, } \\
\text { como: } \\
1 . \quad \text { Título e } \\
\text { informações básicas. } \\
2 \text {. Textos } \\
\text { exploratórios (vamos } \\
\text { investigar o que? } \\
\text { Conhecendo o tema). } \\
3 . \quad \text { Vamos explorar? } \\
\text { (atividades) } \\
4 \quad \text { Orientação para os } \\
\text { docentes. } \\
5 . \quad \text { Dicas para os } \\
\text { alunos. }\end{array}$ \\
\hline $\begin{array}{l}\text { Fonte de } \\
\text { proposição de } \\
\text { problemas }\end{array}$ & $\begin{array}{l}\text { A matemática se } \\
\text { desenvolveu } \\
\text { continua a se } \\
\text { desenvolver partindo } \\
\text { da resolução de } \\
\text { problemas. Mediante } \\
\text { as } \\
\text { atividades/problemas } \\
\text { o aluno deverá } \\
\text { levantar hipóteses e } \\
\text { testar suas hipóteses, } \\
\text { afim de achar a } \\
\text { solução do problema. }\end{array}$ & $\begin{array}{l}\text { Clairaut (1892); } \\
\text { Meserve (1980) } \\
\text { Roque (2012); Ponte, } \\
\text { Brocado e Oliveira } \\
\text { (2016); Valdés (2002); } \\
\text { Ávila (2004); Ponte, } \\
\text { Oliveira e Varanda } \\
\text { (2003); Miguel e } \\
\text { Miorim (2017) }\end{array}$ & $\begin{array}{l}\text { O caderno que propomos é } \\
\text { composto de problemas } \\
\text { históricos a serem } \\
\text { investigados com o apoio } \\
\text { das TDIC via IM. }\end{array}$ \\
\hline $\begin{array}{l}\text { Simula o } \\
\text { trabalho do } \\
\text { matemático } \\
\text { (matemática } \\
\text { genuína) }\end{array}$ & $\begin{array}{l}\text { Permite ao aluno } \\
\text { simular a atividade de } \\
\text { um pesquisador } \\
\text { matemático, não nos } \\
\text { limites do } \\
\text { conhecimento, mas } \\
\text { tão rigoroso quanto } \\
\text { possível. }\end{array}$ & $\begin{array}{l}\text { Fossa (2008); Ponte, } \\
\text { Brocado e Oliveira } \\
\text { (2016); Borba e } \\
\text { Penteado (2012). }\end{array}$ & $\begin{array}{l}\text { Propomos atividades que } \\
\text { estejam estruturadas de tal } \\
\text { forma que o aluno se ache } \\
\text { em uma situação existencial } \\
\text { análoga à do pesquisador } \\
\text { da matemática trazendo } \\
\text { para a sala de aula o } \\
\text { espírito da atividade } \\
\text { matemática genuína, } \\
\text { tratadas, especialmente, } \\
\text { nos itens reflexões e testes } \\
\text { das atividades. }\end{array}$ \\
\hline $\begin{array}{l}\text { Promover } \\
\text { interação } \\
\text { aluno/professor } \\
\text { na aula de } \\
\text { matemática }\end{array}$ & $\begin{array}{l}\text { Transformação da } \\
\text { relação ensino e } \\
\text { aprendizagem devido } \\
\text { a utilização da HM, } \\
\text { TDIC e IM, mudança } \\
\text { dos papeis arquétipos } \\
\text { de professor e aluno } \\
\text { frente ao } \\
\text { conhecimento. } \\
\text { Professor mediador } \\
\text { aluno não receptor, } \\
\text { mas ativo, produtor de } \\
\text { conhecimento sob } \\
\text { orientação. }\end{array}$ & $\begin{array}{l}\text { Allevato (2005); } \\
\text { Miguel e Miorim } \\
\text { (2017); Ponte, } \\
\text { Brocado e Oliveira } \\
\text { (2016); Fossa, } \\
\text { Mendes e Valdés } \\
\text { (2006) }\end{array}$ & $\begin{array}{l}\text { O produto educacional } \\
\text { prevê um guia para o } \\
\text { professor que o oriente } \\
\text { frente ao papel que ele } \\
\text { desenvolve e também para } \\
\text { os alunos nas atividades. }\end{array}$ \\
\hline
\end{tabular}

Fonte: Elaborado pelos autores 
Frente a tais aspectos e argumentos concernentes simultaneamente à tríade de tendências que fundamentam conexas a investigação-histórica-com-tecnologia vale ressaltar que a HM vem como elemento orientador na elaboração das tarefas acionando um processo de produção de conhecimento que prima por posicionamento crítico do indivíduo que investiga com observação, dinamismo e experimentação apoiado pelas TDIC que pode otimizar o tempo despendido em processos automatizados pesquisando situações ocorridas ao longo da HM numa busca ativa do conhecimento. Para tanto, na investigação-histórica-com-tecnologia almeja-se não exclusivamente recapturar experiência antiga, mas gerar nova, valorizando a matemática como empreendimento cultural-humano sendo a cultura informática uma forma de assimilação de conhecimento. Nesse sentido, se realça com as TDIC o componente visual e se automatizam os processos de rotina concentrando a atenção no pensamento criativo provocando mudanças pedagógicas sem automatizar o ensino em que a unidade básica de produção de conhecimento é o ser social composto por um coletivo pensante propiciado pela faceta investigativa.

Os pressupostos revelados propõem, portanto, que a investigação-histórica-comtecnologia deve ser feita mediante a realização de atividades que envolvam pesquisa histórica (de problemas) explorada num processo investigativo tal como o matemático do passado (não nos limites do conhecimento) com ou sem tecnologia a fim de produzir conhecimento matemático. Desse modo, parte da premissa de estudo histórico que, em nosso caso, foi desenvolvido sobre o alicerce das unidades temáticas da BNCC, a qual será detalhada a seguir.

\subsubsection{A BNCC e as unidades temáticas de matemática para o ensino fundamental anos finais.}

Apesar da BNCC ser um documento recente, a sua seguridade vem da década de 60 pelas previsões da Lei $n^{\circ} 4.024$, de 20 de dezembro de 1961, que fixava as Diretrizes e Bases da Educação Nacional. A Lei n 5.692, de 11 de agosto de 1971, que rege as Diretrizes e Bases para o ensino do antigos $1^{\circ}$ e $2^{\circ}$ graus, tratava pela primeira vez na legislação educacional de núcleo comum, obrigatório e da parte diversificada em todo o Brasil. Na Constituição Federal de 1988, no seu art. 210, foi instituído o conceito da formação básica comum, associado à fixação de conteúdos mínimos para o ensino 
fundamental, que posteriormente é tratada na Lei de Diretrizes e Bases da Educação Nacional (LDB), aprovada pela Lei n 9.394, de 20 de dezembro de 1996.

Os Parâmetros Curriculares Nacionais (Brasil, 1997), resumem-se a explicar a base nacional comum, porém esse método não foi aceito pelo Conselho Nacional de Educação (CNE) que, logo em seguida (1998), emitiu as Diretrizes Curriculares Nacionais abrangendo tanto o ensino fundamental quanto o médio, em decorrência da Lei $n^{\circ} .9 .131 / 95$, ambas anunciando a necessidade de se formular posteriormente uma base nacional comum. Depois da Emenda Constitucional $n^{\circ} 59$, aprovada em 2009, o CNE emitiu uma diretriz geral para a educação básica (Resolução CNE/CEB n 4/2010), e diretrizes específicas para o ensino fundamental de 9 (nove) anos (Resolução CNE/CEB n 7/2010) e para o ensino médio (Resolução CNE/CEB n²/2012). Todas estas diretrizes anunciam a necessidade da construção de uma base nacional comum. Assim sendo, a diretriz sobre a BNCC deve ser vista como uma decorrente complementação destas diretrizes. Essa complementação, necessidade que já estava presente nas resoluções do CNE, foi consagrada no texto da Lei $n^{\circ} 13.005 / 2014$, que aprovou o novo Plano Nacional de Educação (PNE).

O documento elaborado pelo Ministério da Educação contendo a proposta da Base Nacional Curricular Comum apenas para a educação infantil e o ensino fundamental, foi conduzido para o Conselho Nacional de Educação em 6/4/2017 e, após a aprovação da proposta, foi encaminhado para realização de audiências públicas com o intuito de colher subsídios e contribuições na sua elaboração. Sendo homologada em 20 de dezembro de 2017 e segundo o CNE, as redes de ensino já podem e devem começar a trabalhar na implementação da política. A revisão de todos os currículos deve acontecer preferencialmente em 2019 e até o prazo máximo do ano letivo de 2020.

No que concerne a matemática, a BNCC (Brasil, 2017) apresentou oito competências a serem desenvolvidas no ensino fundamental anos finas. Para garantir o pleno desenvolvimento dessas competências, os componentes curriculares da BNCC, apresentam um conjunto de habilidades as quais relacionam-se com diferentes objetos de conhecimento que, agrupados, são organizados em unidades temáticas. Para matemática, como dito, são 5 unidades (Números; Álgebra; Geometria; Grandezas e Medidas; Probabilidade e Estatística).

Vale ressaltar que em Silva (2019) a apreciação das demais unidades temáticas estão presentes no produto educacional produzido mas, como aqui falamos de parte dele, nos resumimos a tratar das duas unidades envolvidas, a saber, Álgebra e Geometria, que se encontram na sequência. 
A Unidade de Álgebra para $8^{\circ}$ ano do ensino fundamental anos finais tem por objetivo que o aluno desenvolva as habilidades de: resolver e elaborar problemas que envolvam cálculo do valor numérico de expressões algébricas, utilizando as propriedades das operações; associar uma equação linear de $1^{\circ}$ grau com duas incógnitas a uma reta no plano cartesiano; resolver e elaborar problemas relacionados ao seu contexto próximo, que possam ser representados por sistemas de equações de $1^{\circ}$ grau com duas incógnitas e interpretá-los, utilizando, inclusive, o plano cartesiano como recurso; resolver e elaborar, com e sem uso de tecnologias, problemas que possam ser representados por equações polinomiais de $2^{\circ}$ grau do tipo $a x^{2}=b$; identificar a regularidade de uma sequência numérica ou figural não recursiva e construir um algoritmo por meio de um fluxograma que permita indicar os números ou as figuras seguintes; identificar a regularidade de uma sequência numérica recursiva e construir um algoritmo por meio de um fluxograma que permita indicar os números seguintes; identificar a natureza da variação de duas grandezas, diretamente, inversamente proporcionais ou não proporcionais, expressando a relação existente por meio de sentença algébrica e representá-la no plano cartesiano; resolver e elaborar problemas que envolvam grandezas diretamente ou inversamente proporcionais, por meio de estratégias variadas. Destes, considerando o conteúdo do presente artigo, escolhemos associar uma equação linear de $1^{\circ}$ grau com duas incógnitas a uma reta no plano cartesiano, com e sem tecnologia.

A unidade temática de Geometria para o $8^{\circ}$ ano do ensino fundamental anos finais tem por objetivo que o aluno desenvolva as habilidades de: demonstrar propriedades de quadriláteros por meio da identificação da congruência de triângulos; construir, utilizando instrumentos de desenho ou softwares de geometria dinâmica, mediatriz, bissetriz, ângulos de $90^{\circ}, 60^{\circ}, 45^{\circ}$ e $30^{\circ}$ e polígonos regulares; descrever, por escrito e por meio de um fluxograma, um algoritmo para a construção de um hexágono regular de qualquer área, a partir da medida do ângulo central e da utilização de esquadros e compasso; aplicar os conceitos de mediatriz e bissetriz como lugares geométricos na resolução de problemas; reconhecer e construir figuras obtidas por composições de transformações geométricas (translação, reflexão e rotação), com o uso de instrumentos de desenho ou de softwares de geometria dinâmica. Destes, tendo em vista o foco deste artigo, escolhemos reconhecer e construir figuras obtidas por composições de transformações geométricas (translação, reflexão e rotação), com o uso de instrumentos de desenho ou de softwares de geometria dinâmica. 
Nessa ótica decidimos por um produto educacional na nossa linha de trabalho (HM, TDIC e IM) que já se adeque a tais fins, em forma de um caderno de tarefas que esteja em plena consonância com a BNCC e que possa ser aplicado pelo professor em sala de aula, propondo que ele esteja desenvolvendo competências e habilidades elencadas na BNCC, particularmente para o $8^{\circ}$ ano.

A seguir, serão apresentadas algumas tarefas que formulamos para que os docentes possam aplicá-las em suas aulas como uma alternativa para o ensino e aprendizagem da matemática na educação básica, particularmente, o bloco II do produto que é intitulado por investigação-histórica-com-tecnologia para unidade de Álgebra e Geometria no $8^{\circ}$ ano.

\subsection{Proposta pedagógica de uso da investigação-histórica-com- tecnologia para o $8^{\circ}$ ano}

Conforme já mencionado, ao analisarmos a BNCC, constatamos que a mesma é organizada pelos cinco eixos estruturantes das unidades temáticas de matemática do ensino fundamental anos finais, a saber: Números, Álgebra, Grandezas e Medidas, Geometria e Probabilidade e Estatística. Porém a própria BNCC (Brasil, 2017, p.272) ressalta que "[...] é fundamental considerar que a leitura dessas habilidades não seja feita de maneira fragmentada" e complementa esclarecendo que "a leitura dos objetos de conhecimento e das habilidades essenciais de cada ano nas cinco unidades temáticas permite uma visão das possíveis articulações entre as habilidades indicadas para as diferentes temáticas" (Brasil, 2017, p. 284). Com isto, entendemos que as unidades temáticas nele elencadas podem ser trabalhadas em conjunto. À luz dessa possibilidade, buscamos desenvolver um caderno de tarefas agrupado em 3 ao invés de 5 blocos tendo em vista a constatação de objeto de conhecimento comum entre elas que passou a ser tema gerador das investigações-históricas-com-tecnologia. No caso do bloco de tarefas aqui exposto, os objetos foram plano cartesiano e transformações geométricas/simetrias. Para abordarmos esses objetos, realizamos um estudo histórico bibliográfico.

O produto em geral (caderno de tarefas) é constituído pelos seguintes elementos: apresentação, fundamentos para abordagem da proposta, orientações ao docente, blocos de tarefas e referências.

Cada bloco de tarefas, incluindo o aqui apresentado, tem os itens: título, objeto de conhecimento, habilidade da BNCC, textos exploratórios I e II, exploração I- atividades 
baseadas nos textos históricos, e exploração II: atividades baseadas na investigaçãohistórica-com-tecnologia.

Esclarecendo, as tarefas referentes às unidades temáticas estão distribuídas de modo que iniciamos com uma denominada exploração I em que o aluno deverá fazer a leitura dos textos com informações históricas seguido por perguntas/pesquisas referentes aos mesmos de forma reflexiva. Posteriormente, há uma tarefa denominada exploração II que deve ser resolvida com apoio da tecnologia para que possamos concretizar o ensino e aprendizagem dos alunos mediante a investigação-histórica-com-tecnologia. Precedem a essas tarefas o estudo histórico de texto exploratório (no caso do bloco II são dois textos). Por fim, existe a dinâmica de socialização e a produção dos relatórios de modo a observar o alcance das habilidades pretendidas.

Tal distribuição se justifica nos fundamentos da proposta que, como dito, se apoia no uso de HM, TDIC e IM. Desse modo, consideramos as etapas de uma aula de investigação matemática que segundo Ponte et al. (2016, p. 25, destaque e adaptação nossa), está dividida em três fases, podendo ser aplicadas em uma aula ou em um conjunto de aulas:

i. Introdução da tarefa, em que o professor faz a proposta à turma, oralmente ou por escrito (seção vamos investigar o que? Conhecendo o tema);

ii. Realização da investigação, individualmente, aos pares, em pequenos grupos ou com a turma toda (vamos explorar? Exploração I e Exploração II);

iii. Discussão dos resultados, em que os alunos relatam aos colegas o trabalho realizado (Dinâmica de grupo);

Destacamos o papel fundamental do professor nesse tipo de aula. Fazendo analogia à determinante presença de um maestro na apresentação de uma orquestra, assim é o professor perante a tarefa sugerida. Para tanto, o professor deve agir dando autonomia aos alunos para não prejudicar a investigação realizada por eles, porém deve intervir orientando de modo que o trabalho dos alunos seja significativo e alcance o objetivo traçado no início da tarefa investigativa. O docente também deve levar em consideração as necessidades particulares de cada aluno, por isso precisa manter uma interação equilibrada com toda a sala. Em suma, o professor, segundo Ponte et al. (2016, p.47), deve "desafiar os alunos, avaliar o seu progresso, raciocinar matematicamente e apoiar o trabalho deles”.

Desse modo, a aplicação das tarefas deve seguir os pressupostos de uma aula de investigação-histórica-com-tecnologia indicados a seguir:

- O professor deverá introduzir a atividade falando o tipo do assunto abordado, do tempo de sua aplicação, dos objetivos a serem alcançados e dividir a sala em pequenos grupos, de no máximo 4 pessoas (o modo de como esses grupos deverão 
ser divididos, será explicitado adiante) e fazer a leitura compartilhada da seção "vamos investigar o quê?" Conhecendo o tema.

- Na segunda fase das investigações, ao realizar a atividade, o grupo deverá levantar argumentos/hipóteses/conjecturas que respondam as perguntas da atividade, a parti da seção "vamos explorar?" Exploração I e Exploração II.

- Os grupos deverão apresentar os resultados encontrados aos colegas por meio de discussões em pequenos grupos;

- Por fim cada aluno deverá produzir um relatório para se verificar se as habilidades foram atingidas conforme consta na BNCC;

No início da aplicação sugere-se que o professor divida a sala em grupos. Recomendamos que cada grupo tenha no máximo quatro alunos de modo que o critério de divisão deles fica a cargo do professor, podendo dividir por afinidade, por sorteio ou da forma que julgar mais apropriada. A socialização do resultado de cada grupo é indispensável nessa etapa de aprendizagem proposta por esses objetos.

No que segue, em referência a aliança entre HM e TDIC via IM, buscamos exibir um exemplar de nossa proposta de investigação-histórica-com-tecnologia juntamente com algumas reflexões e orientações para desenvolvimento da mesma à luz da fundamentação apresentada. Desse modo apresentamos o segundo bloco de tarefas do produto educacional (o material na íntegra encontra-se em Silva, 2019), produzido como podemos ver na figura 1. Para sua aplicação são sugeridas 09 aulas de 50 minutos cada considerando os seguintes conhecimentos prévios: plano cartesiano, coordenadas cartesianas, conceito de função, fórmula de função afim. 


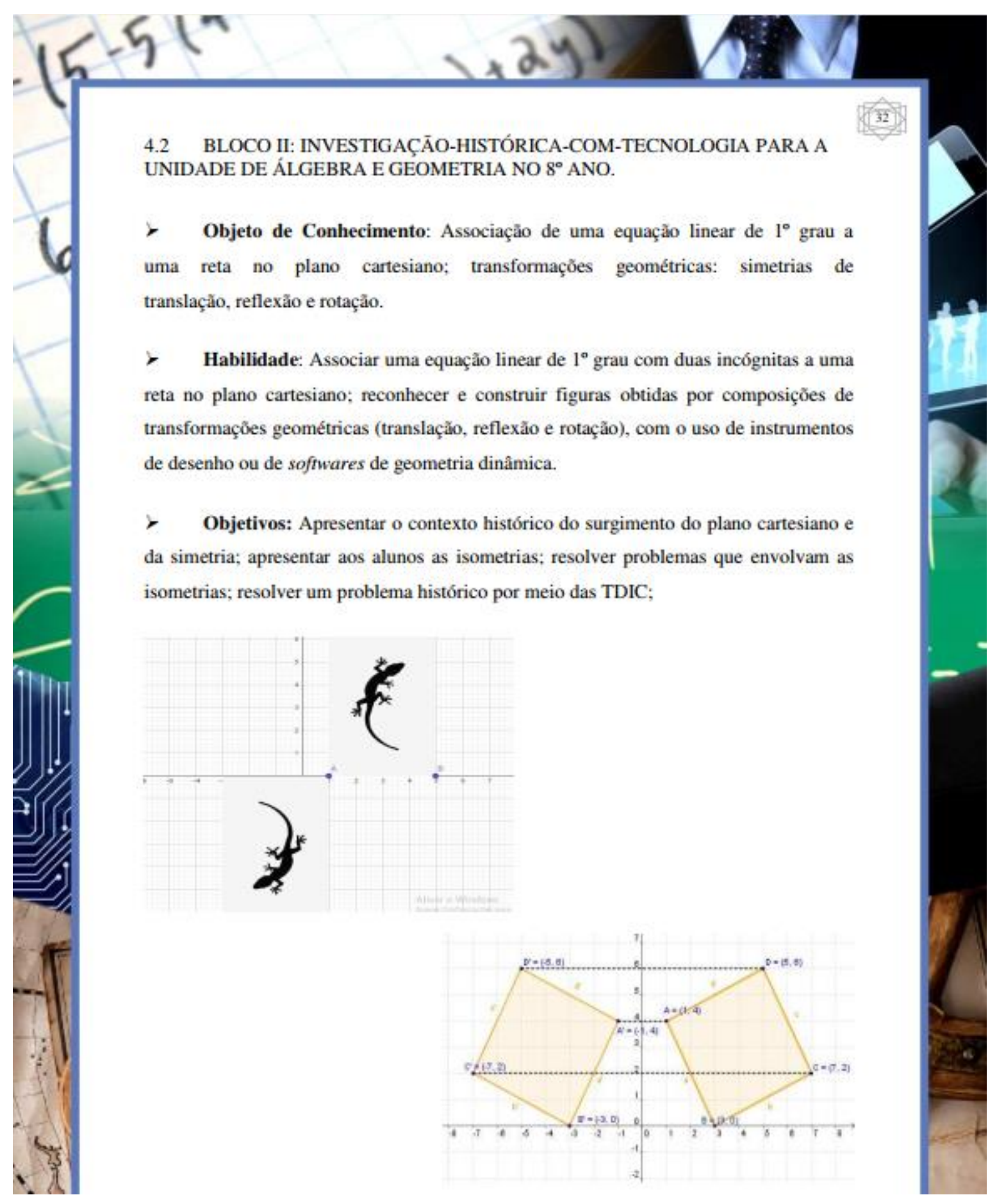

Figura 1: Capa do bloco II de tarefas

Fonte: Silva (2019)

De fato, o bloco de tarefas intitulado por investigação-histórica-com-tecnologia para unidade de Álgebra e Geometria no $8^{\circ}$ ano inicia com a exposição dos objetos de conhecimentos a serem tratados, que constitui a gênese investigativa do bloco e elo entre as unidades temáticas, as habilidades relacionadas e o objetivo a ser alcançado que condiz com a proposta de conexão entre HM, TDIC e IM à medida que busca resolver problemas 
que tratam de plano cartesiano e transformações geométricas tendo em vista uma investigação histórica contextualizada.

Caso o professor identifique que sua turma tenha deficiência nos assuntos de coordenadas e de função afim, ele pode fazer uma revisão antes da aplicação deste material.

Segue a esta etapa a introdução de um recorte histórico com textos exploratórios em que se propõe iniciar a investigação, como pode ser visto na figura 2 adiante. De fato, isto condiz com as orientações da $1^{\text {a }}$ fase de uma aula de investigação matemática como trata Ponte et al. (2016) à medida que há a introdução da tarefa de modo que o professor faz a proposta à turma, oralmente ou por escrito, por exemplo, neste caso, por questionamentos de sondagem sobre o assunto e leitura coletiva.

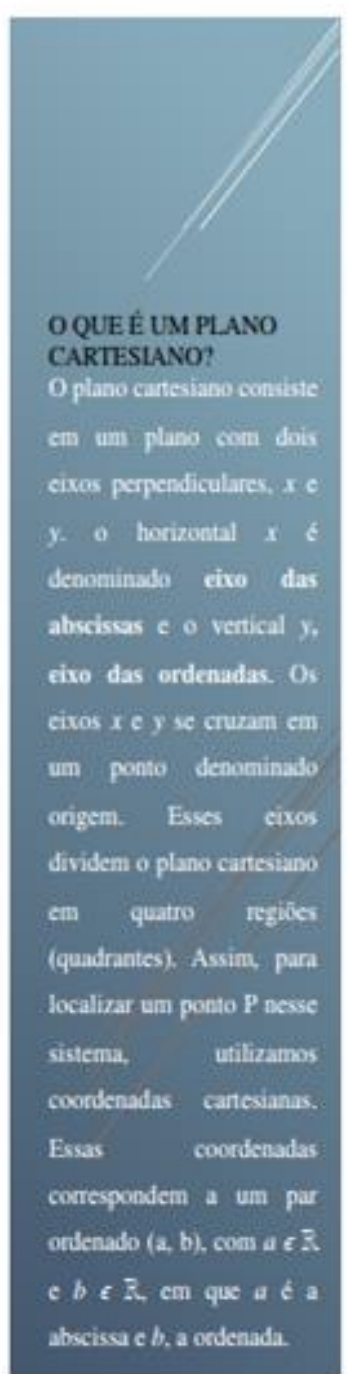

VAMOS INVESTIGAR O QUE? CONHECENDO OS TEMAS.

\section{TEXTO EXPLORATÓRIO 1}

Antigamente a ideia de coordenadas foi usada pelos egípcios $\mathrm{e}$ romanos na agrimensura e pelos gregos na confeç̧̧̉o de mapas. Também no planejamento dass cidades, por exemplo, os romanos consideravam dois eixos perpendiculares a que se referiam a futura posiçào de casas, praças, estradas, entre outras. Atualmente ele $\hat{e}$ utilizado para determinar a posiçảo de pessoa/lugar/objeto/fenômeno na superficie da terra, a exemplo do jogo de xadrez em que é usado para deterninar a localizaçào das peças no tabuleiro por números e letras, bem como na arquiteturalartes pot meio da simetria, entre outros exeaplos.

Um dos primciros autores a utilizar as coordenadas $\mathrm{em}$ seus trabalhos foi Nicole Oresme (1320-1382) que representou graficamente como um elemento descritivo da variaçāo de uma magnitude $\mathrm{em}$ funçầo de outra magnitude, ou seja, Oresme confrontou a variável dependente (latitude), que é proporcional à intensidade ou amplitude

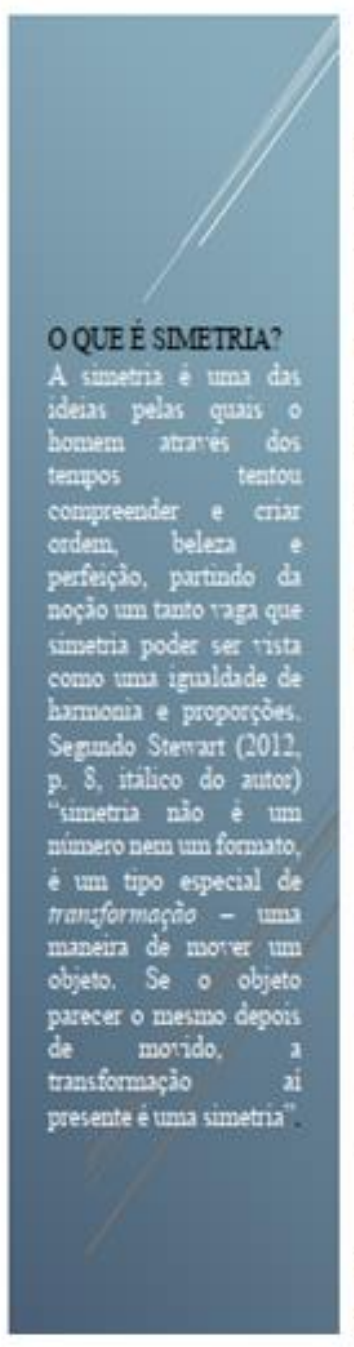

\section{TEXTO EXPLORATÓRIO II}

A simetria foi primeiramente constatada em desenhos, pinturas, esculturas e construçōes de povos antigos. Um dos exemplos mais antiģos que podemos citar $\mathrm{em}$ relaçấ as transformaçōes geométricas $\hat{c}$ a pintura rupestre do Abrigo de Rock El Buey na Bolivia situada na froatcira dos departamentos de Cochabamba e Santa Cruz Ela exibe uma grande variedade de pinturas, provavelmente todas pertencentes a um periodo pré-hispànico.

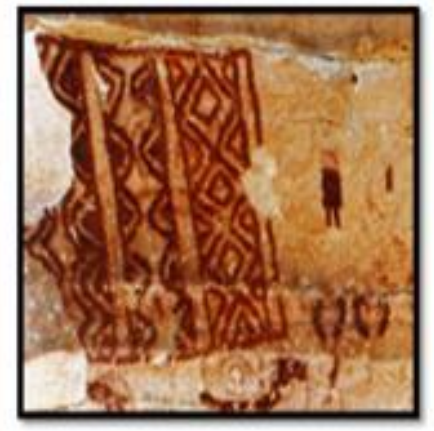

A figura a seguir é uma imagem no raso de prata do Rei sumério Entemena. Observamos que ao

Figura 2: Seção Vamos Investigar: Conhecendo os temas (parte dos textos exploratórios I e II) Fonte: Silva (2019) 
Este elemento do bloco de tarefas intui a aliança entre HM, TDIC e IM pela inicialização do estudo dos problemas históricos e é seguido da etapa Vamos Explorar que traz indagações reflexivas sobre os temas de modo a conhecer e abordar o processo investigativo, conforme se observa na figura 3.

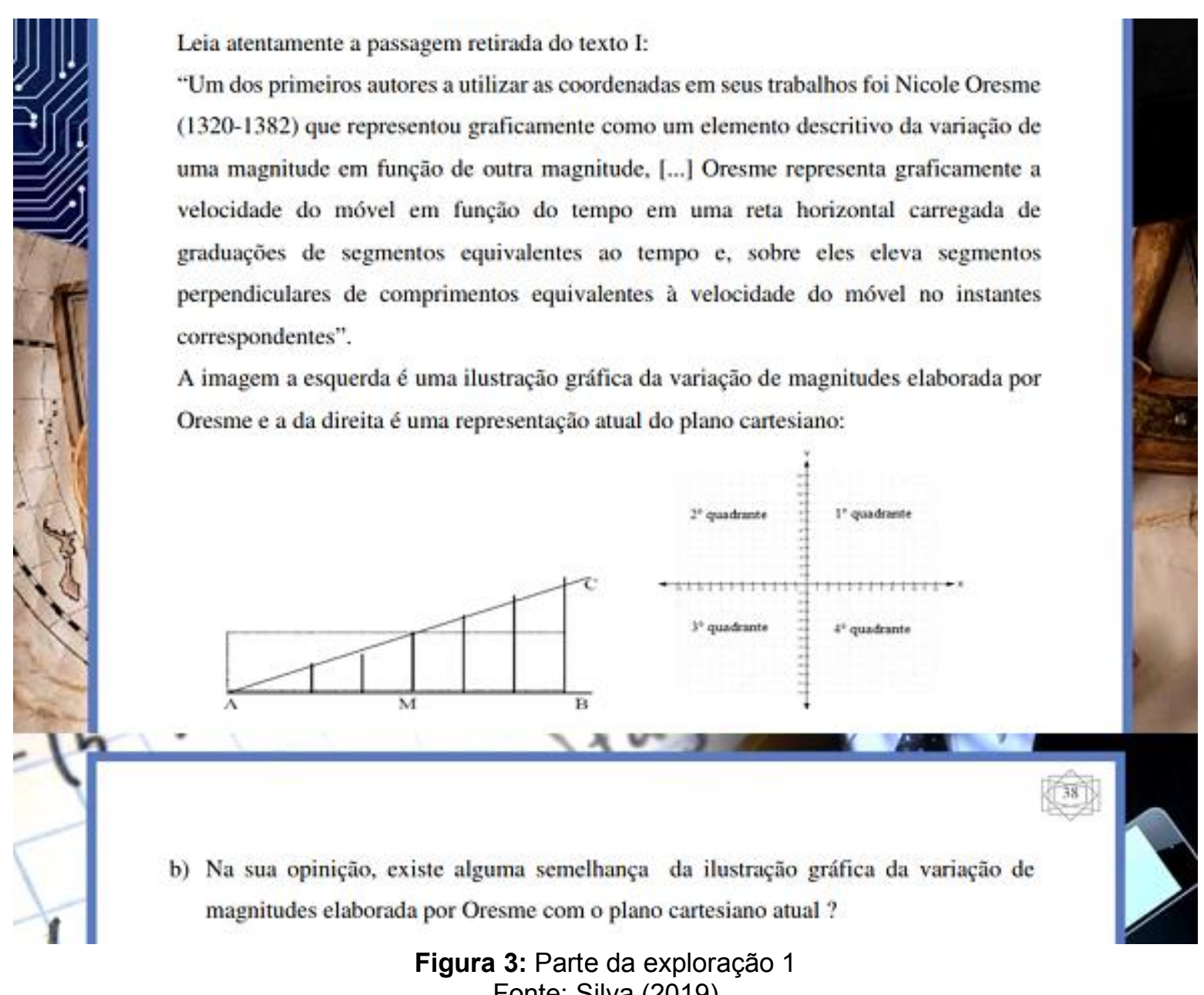

Fonte: Silva (2019)

Os questionamentos postos, tanto na Exploração 1 quanto a 2, almejam levantar conjecturas e formular hipóteses sobre os temas a serem investigados como vemos ainda na figura 4. Realmente, Ponte et al. (2016) apontam que a segunda fase do processo investigativo na sala de aula deve prever a realização da investigação propriamente dita, seja individualmente, aos pares, em pequenos grupos ou com a turma toda. Além disso, nas indagações presentes nestas explorações encontra-se a apresentação da matemática como uma criação humana, sendo a história a fonte de proposição de problemas investigativos (Miguel \& Miorim, 2017), já aqui também com apoio da tecnologia do GeoGebra. 


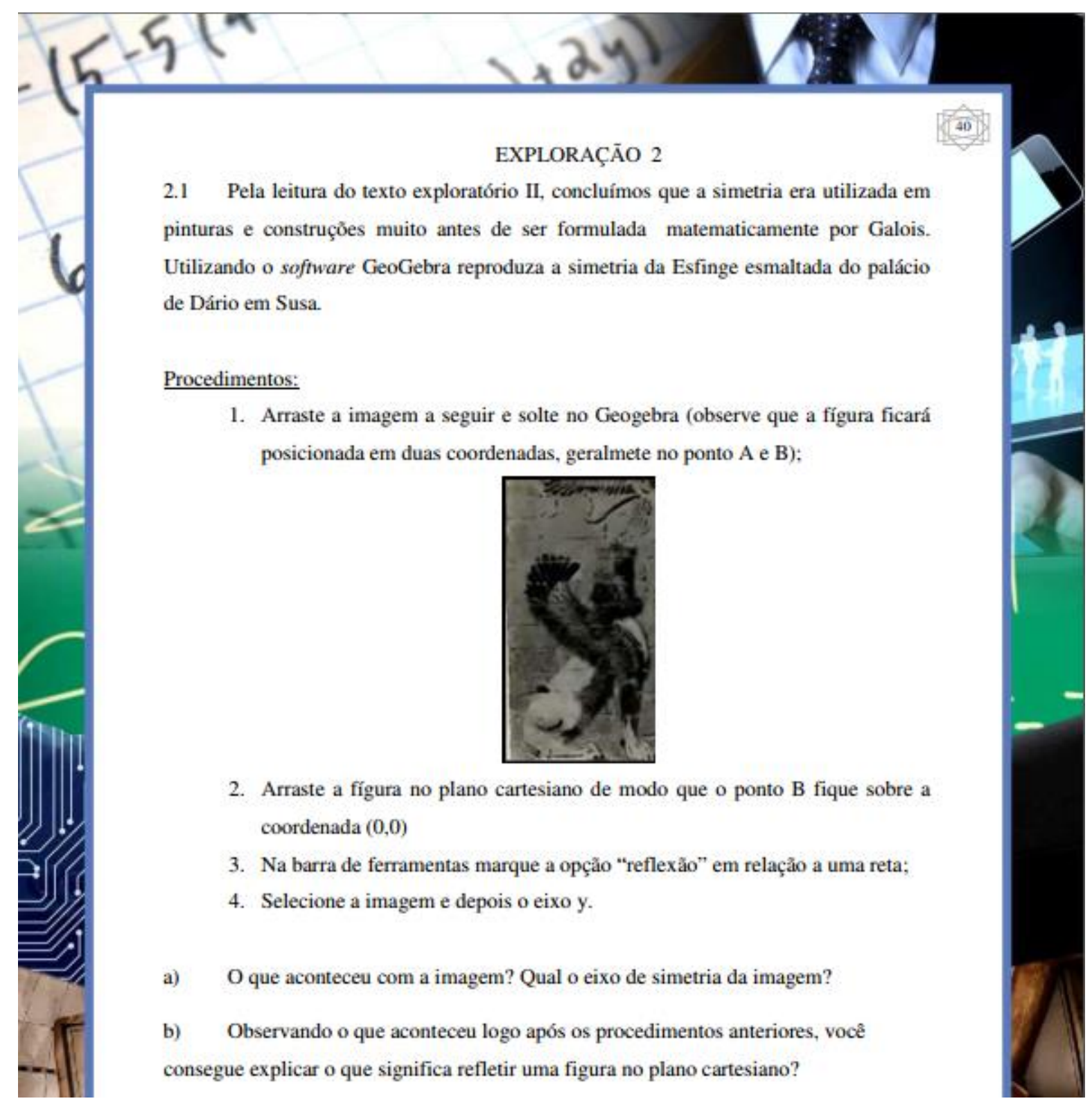

Figura 4: Parte da exploração 2 Fonte: Silva (2019)

Vale ressaltar ainda que na exploração 2 são acrescentados procedimentos para o processo investigativo dos problemas históricos propostos, também levados ao contexto atual, buscando apoio da tecnologia do software GeoGebra para as pesquisas realizadas, conforme trata a figura 5 a seguir. 
2.3 Rotacionando um reta cujas coordenadas são os pontos $\mathrm{A}(0,2)$ e $\mathrm{B}(3,2)$, definida pela equação $\mathrm{y}=2$.

\section{Procedimentos:}

1. Marque a opção "reta" na barra de ferramentas do Geogebra;

2. Na janela de visualização marque os pontos $\mathrm{A}$ e depois o B conforme as coordenadas: $\mathrm{A}(0,2)$ e $\mathrm{B}(3,2)$.

3. Novamente na barra de ferramentas marque a opção "rotação em torno de um ponto";

4. Selecione a reta e depois o ponto B, na caixa de diálogo que abrirá, selecione a opção sentido horário e o ângulo $90^{\circ}$.

a) Houve alteração na direção e no sentido da reta após a rotação? Explique.

b) O que aconteceria se a roração fosse de $180^{\circ}$ no sentido horário?

c) Observando o que aconteceu logo após os procedimentos anteriores, você consegue explicar o que significa rotacionar uma reta plano?

Figura 5: Procedimentos

Fonte: Silva (2019)

Desse modo, a investigação-histórica-com-tecnologia para unidades de Álgebra e Geometria se concretiza com a promoção do conhecimento investigativo simulando o trabalho do matemático (matemática genuína) com a interação aluno/professor (humano) na aula de matemática e mais ainda de humano e não humano (software GeoGebra) num coletivo pensante (seres-humanos-com-mídia) como trata Borba e Penteado (2012).

$\mathrm{O}$ professor pode ainda usar um vídeo tutorial para familiarizar os alunos com o software GeoGebra² ${ }^{2}$ A versão utilizada nas atividades a serem desenvolvidas foi a 6.0.462.03.

Recomenda-se que a atividade encerre com a produção de um relatório como podemos ver na figura 6 que segue.

2 Disponível no link: https://youtu.be/iGnNEnsod 0

${ }^{3}$ Disponível no link: https://download.geogebra.org/installers/6.0/ 
Relatório do Bloco II

Redija um relatório por meio de um texto contínuo escrevendo com suas palavras o que você entendeu nessa atividade de modo que você aborde os seguintes pontos

i. Você consegue associar uma equação linear de $1^{\circ}$ grau com duas incógnitas a uma reta no plano cartesiano?

ii. Você consegue reconhecer e construir figuras obtidas por composições de transformações geométricas (translação, reflexão e rotação)?

Para isso descreva tudo que você aprendeu no Bloco de atividades II.

Figura 6: Relatório

Fonte: Silva (2019)

Esse relatório condiz com a $3^{a}$ fase da aula de investigação matemática proposta por Ponte et al. (2016) que orientam que haja uma discussão dos resultados, em que os alunos relatam aos colegas o trabalho realizado, nesse caso, destacando o conhecimento produzido sobre os objetos de conhecimentos de plano cartesiano e transformações geométricas como simetria, tendo em vista o desenvolvimento das habilidades de associar uma equação linear de $1^{\circ}$ grau com duas incógnitas a uma reta no plano cartesiano; e ainda reconhecer e construir figuras obtidas por composições de transformações geométricas, com o uso de instrumentos de desenho ou de softwares de geometria dinâmica, conforme preconiza a BNCC (Brasil, 2017).

Uma explanação sobre o assunto pode ser sugerida aos alunos na página Sala de ajuda: Isometrias, pertencente ao Clubes de MATEMÁTICA da OBMEP, em que são apresentadas algumas definições e propriedades básicas de geometria, mais especificamente de transformações geométricas no plano cartesiano ${ }^{4}$. Outra opção é a página Sala para leitura: Simetria uma breve apresentação. Nesta página encontramos de forma sucinta uma apresentação sobre o assunto de simetria ${ }^{5}$.

Além disso, há alguns outros links bastante interessantes para explorar a arte de Escher, são eles: Conhecendo Escher e suas obras ${ }^{6}$; Vídeo Escher e a Geometria7; e ainda Vídeo Inspirations ${ }^{8}$ que é um vídeo curta-metragem do cineasta espanhol Cristóbal Vila que

\footnotetext{
${ }^{4}$ Disponível no link: http://clubes.obmep.org.br/blog/sala-de-atividades-isometrias/.

${ }^{5}$ Disponível no link: http://clubes.obmep.org.br/blog/sala-para-leitura 008-simetria-uma-breve-apresentacao/.

${ }^{6}$ Disponível no link: http://clubes.obmep.org.br/blog/sala-de-atividades-pavimentacao-sala-2/

${ }^{7}$ Disponível no link: http://clubes.obmep.org.br/blog/video-6/

${ }^{8}$ Disponível no link: $\underline{\text { http://clubes.obmep.org.br/blog/video-007/ }}$
} 
celebra a Arte Matemática de Maurits Cornelis Escher. Consideramos esta ser uma forma de se trabalhar as transformações geométricas em obras de artes atuais, fazendo com o aluno possa fazer um comparativo com as obras antigas que ele estudou no caderno de tarefas e apresentando ainda como a matemática está presente em nossas vidas.

\section{CONCLUSÃO}

Ao propor a investigação-histórica-com-tecnologia na exploração de objetos de conhecimentos como transformações geométricas no plano cartesiano, chegamos à articulação de unidades temáticas conforme preconiza a BNCC, particularmente, as unidades de Álgebra e Geometria do $8^{\circ}$ ano do ensino fundamental. Neste artigo vimos que um veículo para tal proposta consistiu na investigação de temas históricos como a história do plano cartesiano e a história da simetria cuja exploração pode ser mediada por tecnologias incluindo software GeoGebra, seja pala investigação de contribuição de personagens, obras ou ainda documentos. Nessa ótica, a proposta pedagógica apresentada se alia a argumentos como ser fonte de proposição de problemas, gerar conhecimento investigativo, simular o trabalho do matemático e promover a interação aluno/professor na aula de matemática, os quais que aludem a conexão entre HM, TDIC e IM.

Como desdobramento desse trabalho acenamos a identificação dessa proposta com a Interface entre História da Matemática e Ensino como proposto por Saito (2016) embasada ainda na Teoria da Objetivação de Radford (2020) aludindo a perspectiva de que a investigação-histórica-com-tecnologia pode gerar labor conjunto que perpassa da objetivação a subjetivação. Nessa direção, supomos que outros resultados podem emergir como fruto de novas aplicações.

\section{REFERÊNCIAS}

Brasil. Ministério da Educação. (1997). Parâmetros Curriculares Nacionais - PCN. Versão final. Brasília, DF. Recuperado de http://portal.mec.gov.br/seb/arquivos/pdf/livro01.pdf

Brasil. Ministério da Educação. (2017). Base Nacional Comum Curricular - BNCC. Versão final. Brasília, DF. Recuperado de http://basenacionalcomum.mec.gov.br/images/BNCC El EF 110518 versaofinal site. $\underline{\mathrm{pdf}}$ 
Borba, M. C., \& Penteado, M. G. (2012). Informática e Educação Matemática. Belo Horizonte: Autêntica.

Carvalho, U. W. (1997). PIGEONHOLE: qual é o significado e a tradução? Tecla sap. Recuperado de http://www.teclasap.com.br/pigeonhole-qual-e-o-significado-etraducao/

Saint-Pierre, C. I. C. (1737). Ouvrajes de morale et de politique. Paris: Rotterdam, J. D. Berman.

Hanzelet, J.A. (1624). Récréation mathematicque composee de plusieurs problemes plaisants et facetieux. Pont-à-Mousson: Graueur de Son Altesse, de L'Vniuerfité.

Gil, A. C. (2007). Como elaborar projetos de pesquisa. São Paulo: Atlas.

Hefez, A. (2007). Indução Matemática. Rio de Janeiro: Sociedade Brasileira de Matemática.

Leurechon, J. (1622). SelectæPropositiones in Tota Sparsim Mathematica Pulcherrimæ. Gasparem Bernardum. Pont-à-Mousson: Mussiponti [Pont-à-Mousson] apud Sebastianum Cramoisy.

Ludke, M., \& Andre, M. E. D. A. (2013). Pesquisa em educação: uma abordagem qualitativa. São Paulo: EpU.

Miguel, A. \& Miorim, M. A. (2017). História na Educação Matemática: proposta e desafios. Belo Horizonte: Autêntica Editora.

Pereira, A. S., Shutsuka, D. M., Parreira, F. J., \& Shitsuka, R. (2018). Metodologia da pesquisa científica. Santa Maria. Ed. UAB/NTE/UFSM.

Ponte, J. P., Brocardo, J. \& Oliveira, H. (2016). Investigações matemáticas na sala de aula. Belo Horizonte: Autêntica Editora.

Radford, L. (2020). Um percurso pela teoria da objetivação. In S. T. Gobara e L. Radford. Teoria da Objetivação: Fundamentos e aplicações para o ensino e aprendizagem de ciências e matemática (pp. 15-42). São Paulo, Brasil: Livraria da Física.

Saito, F. (2016). Construindo interfaces entre história e ensino de matemática. Ensino de Matemática em Debate. Recuperado de https://revistas.pucsp.br/emd/article/view/29002/20273

Silva, A. L. F. (2019). História da matemática, tecnologias digitais e investigação matemática no ensino de unidades temáticas de matemática da BNCC para o $8^{\circ}$ ano. (Dissertação de Mestrado em Ensino de Ciências Naturais e Matemática). Universidade Federal do Rio Grande do Norte, Natal. 


\section{TÍTULO DA OBRA}

\section{NOTAS}

Investigação-histórica-com-tecnologia para a unidade de álgebra e geometria no $8^{\circ}$ ano

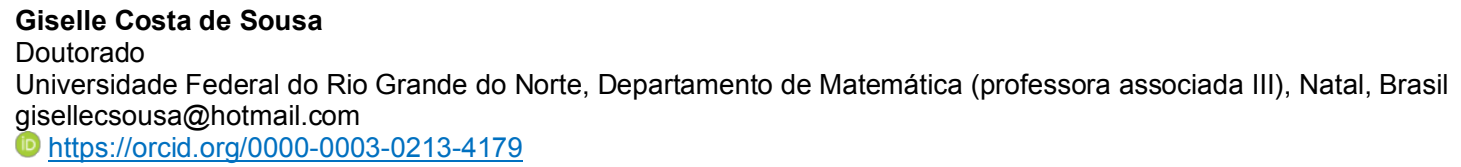

Alison Luan Ferreira da Silva

Mestrado

Secretaria Estadual de Educação e Cultura do Rio Grande do Norte, Natal, Brasil

alisonfera2007@gmail.com

(1) https://orcid.org/0000-0003-4763-8629

Endereço de correspondência do principal autor

Rua Cirilo Moreira, 261, CEP 59062-130, Natal, RN, Brasil.

\section{AGRADECIMENTOS}

Não se aplica.

\section{CONTRIBUIÇÃO DE AUTORIA}

Concepção e elaboração do manuscrito: G. C. Sousa, A. L. F. Silva

Coleta de dados: A. L. F. Silva

Análise de dados: G. C. Sousa, A. L. F. Silva

Discussão dos resultados: G. C. Sousa, A. L. F. Silva

Revisão e aprovação: G. C. Sousa, A. L. F. Silva

\section{CONJUNTO DE DADOS DE PESQUISA}

Todo o conjunto de dados que dá suporte aos resultados deste estudo foi publicado no próprio artigo.

\section{FINANCIAMENTO}

Não se aplica.

\section{CONSENTIMENTO DE USO DE IMAGEM}

Não se aplica

\section{APROVAÇÃO DE COMITÊ DE ÉTICA EM PESQUISA}

Não se aplica.

\section{CONFLITO DE INTERESSES}

Não se aplica.

LICENÇA DE USO - uso exclusivo da revista

Os autores cedem à Revemat os direitos exclusivos de primeira publicação, com o trabalho simultaneamente licenciado sob a Licença Creative Commons Attribution (CC BY) 4.0 International. Estra licença permite que terceiros remixem, adaptem e criem a partir do trabalho publicado, atribuindo o devido crédito de autoria e publicação inicial neste periódico. Os autores têm autorização para assumir contratos adicionais separadamente, para distribuição não exclusiva da versão do trabalho publicada neste periódico (ex.: publicar em repositório institucional, em site pessoal, publicar uma tradução, ou como capítulo de livro), com reconhecimento de autoria e publicação inicial neste periódico.

PUBLISHER - uso exclusivo da revista

Universidade Federal de Santa Catarina. Grupo de Pesquisa em Epistemologia e Ensino de Matemática (GPEEM). Publicação no Portal de Periódicos UFSC. As ideias expressadas neste artigo são de responsabilidade de seus autores, não representando, necessariamente, a opinião dos editores ou da universidade.

EDITOR - uso exclusivo da revista

Méricles Thadeu Moretti e Rosilene Beatriz Machado

HISTÓRICO - uso exclusivo da revista

Recebido em: 07-04-2020 - Aprovado em: 10-02-2021 